\title{
Author's Digression in the English Literary Text Space: Types of Cohesion
}

\author{
Iryna Arkhipova \\ Horlivka Institute for Foreign Languages HSEE "Donbas State Pedagogical University" \\ Bakhmut, Ukraine \\ Email: englishirinaa@gmail.com
}

Received: $1 / 19 / 2021$

Accepted: 8/19/2021

Published: 9/24/2021

\section{Abstract}

One of the most critical problems of the Linguistics of text is the structure study of the literary text, principles of its organization following the rules of the compositions that suggest splitting the linguistic work into the interconnected parts. In this regard, it is necessary to research the individual compositional and significant elements of the text and their role in forming the whole work. The paper focuses on revealing structural and syntactic properties of the author's digressions, namely, detecting such concepts as integration/non-integration of the author's digressions in the English literary prose. Integrated and non-integrated types of author's digressions into the academic space of the text have been distinguished based on interpretativetextual and compositional analysis. The analysis of the text-forming function of the author's digression contributed to defining the features of the cohesion of the literary text and included in its elements. The analysis results show that the author's digressions can be both integrated and non-integrated. Non-integration of the author's digression lies in their composition-semantic independence, and integrated author's digressions are the ones that the author weaves into the text with different types of cohesion. This research promotes the studies of the cognitive aspect of the author's digression in the different genres literary texts of English and American prose.

Keywords: Author's digression, autosemantic, coherence, cohesion, integrated / non-integrated, literary text

Cite as: Arkhipova, I. (2021). Author's Digression in the English Literary Text Space: Types of Cohesion. Arab World English Journal, 12 (3) 201-215.

DOI: https://dx.doi.org/10.24093/awej/vol12no3.14 


\section{Introduction}

The interest in the study of the text in Linguistics does not weaken. It is determined that the last one is the scope of implementation and the form of the actual existence of the language; in the first place, it concerns the literary text. The text is the whole, the only language work. However, at the same time, it is a combination of the statements of the various subject-language plans, with complicated and dynamic relations between them (Turowetz, 2017; Crofft, 2004; Gordon, 1966; Green, 1990). The text consists of relatively large and relatively small parts, which are called components. The text has highlighted different segments by form (description, dialogue, monologue, inner monologue). These segments differ from one another in the language design and with the practical orientation, different significance in work, and some other indicators (Bošković, 2016; Krongauz, 2001; Britta, 2016; Gumperz, 1982). The distinct elements are the principle of the composition and the primary structural law of the literary text. This law provides the constant predictability resistance - "permanent informativeness" for the literary text (Crofft, 2004, p. 390). Composition implements the author's attitude to the content (Britta, 2016, p. 246). In implementing the artistic conception, specific ideas for each element of the composition and linguistic structure the right place are given (Bošković, 2016; Turowetz, 2017; Bal, 2009; Kosmeda, 2017; Kramar, 2017).

In the philological works on the theory of the composition of the literary text, the author's speech and the image of the author linguists highlighted in the various aspects: from the perspective of narratology of the interpreted concept of "author's point of view," forms and types of the author's speech (Arnold, Vinogradov, Kukharenko); in the syntactic and stylistic aspect the peculiarities of the composition as a method of artistic theme deployment (Zhyrmunskiy), "text modality" and the "author's image" as the style-creating category of text (Vinogradov, Solhanyk). However, the author's digressions, functions, and communication strategies for the inclusion to the semantic space of the literary text did not receive enough highlights from the positions of linguopragmatic and communicative-functional approaches.

\section{Research objectives and research purpose}

The object of the work is the author's digression in English prose. The material of the study is English literary prose of the XIX-XX centuries. We determine the author's digression as an autosemantic compositional unit of a literary text. Digression ensures a semantic relationship of different text elements, performs emotional and esthetic, phatic, and cognitive functions, and is considered explicit about defining the author's and reader's images.

The purpose of the work is the systematizing and classifying of the author's digressions in the literary English prose texts from the perspective of a comprehensive approach oriented to identify their linguopragmatic properties, namely, detection of such concepts as integration/nonintegration of the author's digression, a study of the types of cohesion of the author's digression in the literary text space. The originality of the work lies in establishing the linguistic and pragmatic properties of the composition-and-plot, composition-and-structural, and compositionand-semantic units of the text.

\section{Literature review}

The author's attitude to the represented reality is transmitted using the author's digression; using them, the author guides the reader to adequate decoding of his communicative intention, 
designs the expected valuation of the described. The author's digressions can be included in any part of the text: introduction, scenario, climax, and denouement. Composition-structural analysis of the studied works showed no stable trend to use the author's digression in specific text segments. The analysis of the text-forming function of the author's digression contributed to defining the features of the cohesion of the literary text and included in its elements.

As revealed by the study, the author's digressions have auto-semantics, but the degree of auto-semantics is different in the author's digression. After Galperin (2004), we define the autosemantics, non-integration of the author's digression on the lexical, grammatical, and semantic levels:

1. On the lexical level - the absence of words and phrases repetition.

2. On the grammatical level - the lack of the deictic units and violation of the uniformity of construction of structural and phraseological unity or paragraph.

3. On the semantic level- maxims not related to the text in generalized formulas.

Thus, the auto-semantics of the author's digression implements. Each syntactic-stylistic type of the author's digression (converged, diverged, or converged-and-diverged) can be integrated or non-integrated.

\section{Methodology}

We reveal the author's digressions by several compositional-semantic and compositionalstructural features with the help of interpretative-textual and semantic analysis of the English literary prose. The prominent features contributed to determining the author's digressions among other included units in the text. The use of compositional analysis allowed to reveal various types of cohesion of the author's digressions with the text.

\section{Findings and discussion}

\section{Non-integrated author's digression}

Non-integration of the author's digression lies in their composition-semantic independence. Thus, in a fragment from the novel by Maugham (2007) "The Moon and Sixpence," we highlighted the converged author's digression that is non-integrated due to the type of inclusion in the text:

The faculty for myth is innate in the human race. It seizes with avidity upon any incidents, surprising or mysterious, in the career of those who have at all distinguished themselves from their fellows, and invents a legend to which it then attaches a fanatical belief. (Maugham, 2007).

The above author's digression consists of a complex structure of sentences: simple, complicated, complex. We define it as non-integrated because it takes the starting position of a paragraph, as well as it is different with conjunctionless, deictic, lexical relation to the previous paragraph. In the following fragment, we selected the author's digressions that are a whole paragraph:

At the first sign of the approach of one of these outrages, all clocks ought to be put back three hours so that everybody might stay in bed until their fury is spent. There is no end to their malice. (Priestley, 2020, p. 74). 
This author's digression is non-integrated concerning the main story. Such utterances are the micro-texts, where morality is expressed based on the human experience (Galperin, 2004).

The author's digressions that are the initial components of a paragraph, as a rule, have the highest degree of auto-semantic compared with the author's digression that creates a paragraph. We believe that most author's digressions presented as the paragraphs are non-integrated. The above examples of the author's digression are auto-semantic; they do not require additional context to realize its content. At the same time, the introduced in the text author's digression has a direct and immediate relation with the overall thematic context.

Let us consider the examples of the convergent non-integrated author's digression: Innocence always calls mutely for protection when we would be so much wiser to guard ourselves against it: innocence is like a dumb leper who has lost his bell, wandering the world, meaning no harm. (Green, 2004, p. 29).

Suffering is not increased by numbers: one body can contain all the suffering the world can feel. (Green, 2004, p. 186).

The above digressions are non-integrated because removing these examples from the text does not change the text's content and the author's digression. These author's digression expresses the standard views on life, human wisdom based on the years of experience.

\section{Integrated author's digressions}

Integrated authors' digressions are woven into the text using different types of cohesion (Dijk, 1980; Givon, 1993). Cohesion is the connectivity of text elements when the interpretation of some text elements depends on the others (Dijk, 1980; Givon,1993). The lexical and semantic repetitions are the means to express cohesion (Krongauz, 2001). Halliday (1976), Redeker (2000) first differentiated cohesion as structural and grammatical cohesion and coherence as meaningful. The semantic side of the cohesion has found the reflection in terms of lexical solidarity, isotopy, recurrence. The orientation of cohesion means caused, above all, it is attributing only to the language level on the background of the detailed analysis of standard text connectors: pronouns, repetitions, coreferential series, conjunctions.

In modern linguistic studies, segmental indications of cohesion are distinguished:

1. Lexical (repeat, synonyms, antonyms, stem words, one-theme words).

2. Grammatical (conjunctions, connecting words, demonstrative pronouns, correlative words, degrees of comparison, parenthetic words, and sentences).

3. Syntactic (word order, order of parts connection, sequence).

4. Stylistic (syntactic parallelism, ellipsis, graduation, interrogative sentences).

5. Supra-segmental (intonation, pauses, accents).

6. Situational (situations, associations).

The linguists have always considered cohesion as the most crucial text category, which mediates the development of the theme and provides the integrity, integration of the text (Selivanova, 2004, p. 115). The cohesion of the text manifests itself in different language levels: semantic, lexical-grammatical, phonological, and orthographic. In the framework of the semantic 
level, we can distinguish the pragmatic. The text segments are related thematically, with a specific set of heroes' motifs found in a different relationship between cultural and social nature and many other factors. The author and the novel's heroes express their attitude to the action, which is happening to its members.

Linguists classified the means of cohesion in the text as traditionally grammatical, performing a text-formation function, logical associative (subtext), image, compositionstructural, stylistic, and rhythm-creating (Scott, 2016; Galperin, 2004). Depending on the actualized by the communicants' information, the following types of cohesion are distinguished: grammatical, semantic, onomasiological, logic, image, connotative, structural and compositional, topical (Scott, 2016; Selivanova, 2004). After M. A. K. Halliday (1976, p.125), we believe that cohesion relations are relations between two or more elements in the text, regardless of the structures. The category of integrity, which is sometimes called "coherence," is usually opposed to the category of cohesion (Troshina, 1982, p. 53). According to Lyons (1963), the differences between cohesion and coherence are identical to the differences in form and content.

Cohesion is the relation of the elements of the text when one is dependent on the other (Galperin, 2004, p. 103). Coherence is the relation brought with something external concerning the text, first of all with the knowledge of its addressee (Galperin, 2004, p. 123). Based on the inside, the addressee can construct certain expectations and finish up the relationship that is not expressed explicitly in the text (Krongauz, 2001, p. 10).

As the study of the literary tests shows, not all author's digressions are not-integrated; many of them are related to the text using cohesion. Let us consider the digressions that are part of the sentence. The following author's digressions are characterized by integration in the general text because the author's digression is only a part of a sentence. It has a grammatical link with the whole sentence and logical and lexical types of coherence between the author's digression and the text of the main story. The example of the convergent author's digression that is the part of the sentence is a fragment of the novel by Kipling (2021) "The Light That Failed":

Since the human soul is finite and not in the least under its command, Dick, advancing, said, "Halloo"! After the manner of schoolboys, and Maisie answered, 'Oh, Dick! (Kipling, 2021).

We believe that this author's digression is an integrated type because the author's digression is a part of the complex sentence; the logical connection of the author's digression with the text of the main story exists. This author's digression could not be removed out of context because the sense is lost. Relation of the author's digression with the text can be grammatical, semantic, and associative.

\section{Grammatical cohesion}

Among the grammatical forms of cohesion, we distinguished connectors and connecting words, deictic means (pronouns, conjunctions), participial phrases. The connectors of the coordinating and subordinating relation actualize the logical cohesion of the author's digression. Among all the conjunctions, the most frequently used are: but, and, for, after all.

Thus, for example, in the following fragment from the novel by Maugham (2007) "The Moon and Sixpence," the cohesion of the author's digression is done with the grammatical 
markers, namely, conjunctive element after all:

I do not know how they got on or what they talked about. After all, there are twenty four hours in the day, and the summits of emotion can only be reached at rare intervals. I can only imagine how they passed the rest time. (Maugham, 2007).

The addresser tries to explain what "the feeling reaches the top only in rare moments, and the day has only twenty-four hours," and so the author "can only imagine what they (the lovers) did all the rest of the time." Thus, the addresser defines the essence of the events that occur.

The author's digression and the main text may be bound and opposed with the conjunction but. As an example, in the novel by G. Greene (2004) "The Quiet American":

But if one writes about war, self-respect demands that occasionally one share the risks. (Green, 2004, p. 136).

The sentence with the conjunction but is the author's digression; it is convergent due to the syntactic-stylistic type. The conjunction but performs its counter function: forms a single unit, and at the semantic level, represents different semantic segments.

In the novel by Maugham (2007), "The Moon and Sixpence," the author included digression in a sentence with a conjunction for:

No one went near the plantation, for, as you know, the natives have a very lively horror of the disease, and in the old days when it was discovered the sufferer was killed; but sometimes, when the village boys were scrambling about the hills, they would catch sight of the white man, with his great red beard, wandering about. (Maugham, 2007).

In this example, the addresser intends to expand the knowledge of the addressee about the horrible disease: leprosy, to supplement information, to show the reaction of the surrounding people to the sick person.

As revealed by the study, the author's digression may not be preceded by a conjunction or a conjunction word. However, the conjunction element author used in the story's text with the author's digression. This fact we can see in the example of the author's digression from the novel by G. Greene (2004) "The Quiet American":

A dollar love, of course, would include marriage, and Junior and Mother's Day, even though later it might consist of Reno, or the Virgin Islands, or wherever they go nowadays for their divorces. A dollar love had good intentions, a clear conscience, and to Hell with everybody. But my love had no intentions. (Green, 2004, p. 55).

The selected text fragment is a converged author's digression. The author weaved it in the main text of the text conjunctionless; the opposite relation is expressed implicitly at the semantic level. Here the author is thinking about the mutual relationship of the material (a dollar love) and spiritual (Mother's Day) in general, without specifying the specific subject of the action. 
In the following fragment from the novel by G. Greene (2004) "The Quiet American," the selected author's digression is included in the text of the main narrative with the punctuation means:

There was nowhere to sit except in the Papal chair, round which a plaster cobra coiled, the marble floor glittered like water, and there was no glass in the windows - we make a cage for air with holes, and man makes a cage for his religion in much the same way with doubts left open to the weather and creeds opening on innumerable interpretations. (Green, 2004, p. 77).

The structural feature of this author's digression is that the author's digression is expressed with the part of the complex sentence and included in this sentence without a conjunction. The author's intention in such an author's digression is to introduce the reader into the atmosphere and guide him to certain conclusions.

In the following example, the author's digression from the novel by Maugham (2007) "The Moon and Sixpence" is included in a sentence without conjunction, which increases its independence, autonomy:

If I am rhetorical, it is because Stroeve was rhetorical. (Do we not know that man in moments of emotion expresses himself naturally in terms of a novelette?). He was like the mystic seeking to describe the ineffable. But one fact he made clear to me: people talk of beauty lightly and having no feeling for words, they use that one carelessly so that it loses its force; and the thing it stands for, sharing its name with a hundred trivial objects, is deprived of dignity. (Maugham, 2007).

The author included this digression in the sentence with a conjunctionless relation, and it is a semantic unit integrated into the narrative. In this example, the addresser-author gives its assessment of the events.

Among the lexico-grammatical means of the inclusion of the author's digression in the text, we selected pronouns: then, here, this, that, his, her. Thus, for example:

I was not fifteen when my father found that I had a lover", she said. "He was the third mate on the Tropic Bird. A good-looking boy". She sighed a little. They say a woman always remembers her first lover with affection, but perhaps she does not always remember him". My father was a sensible man". "What did he do"? I asked. (Maugham, 2007).

The author's digression weaves in the main text of the story with the pronoun they; with this, the author generalizes the women's psychology.

As our research suggests, personal and possessive pronouns are the most widely used among the pronoun communication methods. We want to mention the demonstrative pronouns, which are also participating as a means of communication, and link the text of the author's digression with the main text. It is about pronouns it, that, this, these, the feature of which is that 
they have a general character relating to the whole text, they are linking several sentences with the one specific content. Here are a few examples of the author's digression where the author used the above pronouns:

They would grow old insensibly; they would see their son and daughter come to years of reason, marry in due course - the one a pretty girl, the future mother of healthy children; the other a handsome, manly fellow, obviously a soldier; and at last, prosperous in their dignified retirement, beloved by their descendants, after a happy, not unuseful life, in the fullness of their age they would sink into the grave. That must be the story of innumerable couples, and the pattern of life it offers has a homely grace. It reminds you of a placid rivulet. (Maugham, 2007).

The selected fragment of the text is a convergent author's digression. The author's digression weaves in the main text of the story with the pronoun that. In this author's digression, the pronoun that refers to the all previous section. Furthermore, inside the author's digression, the addresser summarizes what he said before.

In the following example, the divergent by style author's digression is a philosophical contemplation of love:

I could not that Strickland had fallen in love with Blanche Strove. I did not believe him capable of love. That is an emotion in which tenderness is an essential part, but Strickland had no tenderness either for himself or for others; there is in love a sense of weakness, a desire to protect, and eagerness to do good and to give pleasure - if not unselfishness, at all events selfishness which marvelously conceals itself; it has in a certain diffidence. These were not traits that I could imagine in Strickland. Love is absorbing; it takes the lover out of himself. It makes a man a little more than himself. (Maugham, 2007).

The structural feature of this divergent author's digression is that the author's digression, which is semantic unity, is scattered through the text. Thus, the demonstrative pronoun combines not only the author's digression and the previous sentence, but it also combines the text into a semantic unit. As you can see from the example, the author logically introduced the digression into the main text, entwined with it, and sealed using the pronouns that, these.

\section{Semantic cohesion}

The semantic cohesion of the text is a semantic relation of its components based on the content of the consistent text fragments and the individually included elements. We can carry it out without externally defined communications (Benedetti, 2015). Situational cohesion is a subtype of semantic cohesion, the criterion to identify the principle of "unity of the situation." The situational cohesion can be detected indirectly as the predictable thematic proximity between the fragments of the text, the very fact of inclusion of which into one text illustrates their semantic proximity (Benedetti, 2015).

We understand the semantic cohesion of the author's digression with the text as a logicalsemantic relation of the text elements based on specific content. We observe the semantic unity 
of the text and the author's digression in the lexical and synonym repetitions. So that the language was clear, logically ordered, we cannot do without the repetition of words, their forms, and derivatives of these words because their use is associated with the structure organization. The meaning of the lexical repetition provides an expression of the present or semantic dismemberment of the language.

Thus, in the following text, we can see the duplication of the lexical item "hate" in the author's digression and in the sentence of the main story:

"How many people have to die before you realize"? But I could tell that it was a hopeless argument. "Realize what, Thomas"?

"That there is no such thing as gratitude in politics" At least they will not hate us like they hate the French. "Are you sure"?

Sometimes we have a kind of love for our enemies, and sometimes we feel hate for our friends.

"You talk like a European, Thomas. These people are not complicated". "Is that what you have learned in a few months? You will be calling them childlike next". "Well in a way..." (Green 2004, p. 161).

The main story sentence contains information about the relationship between people and government representatives (At least they will not hate us like they hate the French), verbalized by lexical item hate.

Let us consider the following example of the author's digression from the novel by Kipling (2021) "The Light That Failed":

This is good, and since it allows, and even encourages, strife, recrimination, and the most brutal sincerity, it does not die but increases and is proof against any absence and evil conduct. (Kipling, 2021).

In the author's digression, the author characterizes the male friendship verbalized in the text phrase a good love. The author passes two ways approaching this phenomenon through the tougher lexicon brutal sincerity. However, the author remains on the side of male friendship, stressing the strength of these relationships with the verb to increase. The author used the lexical item love in the main text and in the author's digression. The author's digression is included in the main narrative with a demonstrative pronoun this regarding the lexical item love that creates the lexical relation and provides the semantic unity of the text with the author's digression.

Sometimes, the author used synonymous repetitions or expressions to relate the author's digression with the main text of the story. In the following example of the author's digression from the novel by Kipling (2021) "The Light That Failed," the author uses the words of the same synonymous field:

Have I killed you?' Revolvers are tricky things for young hands to deal with. Maisie could not explain how it had happened. (Kipling, 2021).

The lexical items revolvers, to kill that refers to the same topic series "crime" provide the 
cohesion of the author's digression with the narration in the text.

\section{Hyponymic cohesion}

Among the author's digression, there are digressions that the author combines with the text using hyponymy. Hyponymy as the genus-species relations is the inclusion of the semantically similar units in the corresponding class names. A hyponym is a concept that expresses a partial essence about the other more general idea, and a hyperonym is a word with a broader meaning that describes the common genus concept, the name of the class (set) of pieces (properties, characteristics).

Here is an example of the hyponymic cohesion from the novel by Maugham (2007) "The Moon and Sixpence":

I do not suppose she had ever really cared for her husband, and what I had taken for love was no more than the feminine response to caresses and comfort, which in the minds of most women passes for it. It is a passive feeling capable of being roused for any object, as the vine can grow on any tree, and the wisdom of the world recognizes its strength when it urges a girl to marry the man who wants her with the assurance that love will follow. It is an emotion made up of the satisfaction, insecurity, pride of property, the pleasure of being desired, the gratification of a household, and it is only by an amiable vanity that women ascribe to its spiritual value. (Maugham, 2007).

In this example, we highlighted the lexical items feminine response to caresses and comfort that are hyponymic to the lexical item of feeling. In the same way, the hyponymic lexical item emotion is presented in the author's digression and feminine response to caresses and comfort in the main story.

We define hyponymy as a one-side replacement: the text may have a possible equivalent replacement of hyponym to hyperonym. The author uses a hyponym in the main text and in the text of the author's digression - a hyperonym. Let us find it on a specific example from the novel by Maugham (2007) “The Moon and Sixpence":

Mrs. Strickland had the gift of sympathy. It is a charming faculty, but one often abused by those who are conscious of its possession: for there is something ghoulish in the avidity with which they will pounce upon the misfortune of their friends so that they may exercise their dexterity. It gushes forth like an oil - well, and the sympathetic pour out their sympathy with an abandon that is sometimes embarrassing to their victims. (Maugham, 2007).

In this fragment of the gift of sympathy is a hyponym towards charming faculty. Thus, the charming faculty is a hyperonym. In the author's digression, the author uses hyperonym, i.e., he seems to summarize what has been said before and operates with more general concepts. The presented class of hyperonym is broader than hyponym has. In most cases, the text mostly has a hyponym and a hyperonym in the author's digression (i.e., turning species under the genus). The author suggests that one of the characters has a gift of sympathy (hyponym). After that, the author's digression takes the word "excellent quality" charming faculty, a hyperonym. There is 
no reverse transition from hyperonym (in the text) to hyponym (in the author's digression). The content of the author's digression itself does not clarify the concepts but describes the lyrical reflections, expression of feelings, emotions.

Sometimes, the author combines digressions with the text by verbalizing emotions, feelings, and moods. Often the author's digression is the original author's emotional reaction to the current events:

Women! I had always thought that to live on a woman's immoral earnings, you must be a strapping flashy fellow with sex appeal, ready with your knife or your gun; it was astonishing that such a puny creature, who might have been a lawyer's clerk from his appearance, could get a footing in such an overcrowded profession. (Maugham, 2004, p. 263).

In this example, the addresser expresses his views: I had always thought that to live on a woman's immoral earnings you must be a strapping flashy to the actions of a character in the novel, I noticed her take something (money) out of her bag and hand it to him. For the author of the text, the very fact that the woman is giving money to the man and that man not only accepts it but can live on them is humiliating. In the author's digression, he provides the characteristics of this type of people (fellow strapping with flashy sex appeal). Therefore, the connecting element between the text and the author's digression is the author's response to the events taking place, i.e., expressing emotion to the previously described fact.

In the following author's digression from the text of the novel by Maugham (2007) "The Moon and Sixpence," the actual attitude of the author towards the depicted in the text character (Strickland) can be found. The author expresses his opinion, pushes the addressee on a detailed estimate:

He was independent of the opinion of his fellows. And it was just that which had most disconcerted me in my dealings with him. When people say they do not care what others think of them, for the most part, they deceive themselves. Generally, they mean only that they will do as they choose, in the confidence that no one will know their vagaries, and at the utmost only that they are willing to act contrary to the opinion of the majority because they are supported by the approval of their neighbors. (Maugham, 2007).

The selected text fragment is the author's digression-philosophical reasoning. The author's position on significance for each person's opinion in the author's digression is updated. The intention of the author's judgments, conclusions was the behavior and life principles of the main character (He was independent of the idea of his fellows). By its content, the author's digression from this or the other side reveals the main character's traits, i.e., describes the subject of the speech. The consistency of this digression with the text is defined first with a commented element (Strickland behavior) and a specific semantic and logical sequence of the described events.

The intention to create the following author's digression is the communicative intention of the author. He also determines its content, i.e., the addresser defines the personal interpretation of the problem, as in the example of the author's digression from the novel by Kipling (2021) "The Light That Failed": 
Sometimes the hull is out of order, and we consult a surgeon; sometimes the rigging; sometimes the engines, and we go to brain specialist; sometimes the look-out on the bridge is tired, and then we see an oculist. A little patching and repairing from time to time is all we want. An oculist, by all means. (Kipling, 2021).

The selected fragment of the text is a divergent author's digression. The sentence (We all want a little patching and repairing from time to time) is auto-semantic, but it is the motivation for the following two sentences - the author's digression. The theme of this sentence becomes the subject of the author's digression. Thus, a chain link of the first sentence develops with the following, with the repetition of the words (little patching and repairing). The author clarified the unity of this digression with the whole text by the unity of the theme specified in the first sentence.

\section{Associative cohesion}

The associative cohesion carries out the relation of the author's digression with the text in some cases. Association as a mental phenomenon is an imaginary relation made by the previous experience. One imagination arising in mind causes the similar one, adjacent or otherwise different. The word in the language is a signal of a particular relation with this or another association. From the very beginning, the possibility of associative imagination with other language units is given the tendency to such convergence (Klimkova, 1991, p. 45).

According to Galperin (2004), such features of the text structure as retrospection, subjectively-appraisal modality, and connotation lie at the foundation of the associative cohesion. Associative cohesion we characterize as the fact that the remote imaginations that are not related to the logical confirmation get apparent relation between the described phenomena. Under the association, we understand the unification of the language units due to the logicalsemantic features.

The presence of associative relations is the mandatory condition to the transfer of the necessary information. Associative relations contribute to the unification of all parts of the text into a single unit. The association is the process programmed by the author of receiving a certain amount of information from the reader's memory, his system of knowledge (associative system). Depending on the source, there is a need to differentiate the two interacting associative systems: background knowledge and a system of text knowledge. This support causes the understanding of the semantic content of the text. The system of text knowledge is individual for each text. It is a complex associative system (system of knowledge), the emergence of which is caused by the understanding of the text information.

Associative relations that appeal to a system of text knowledge are textual ones. Thus, the associative relations in the text cause the emergence of a certain amount of information in the mind of the reader not from the linear sequences of the linguistic signs but using two sources: on the one hand, from the system of background knowledge (long-term memory), on the other hand, from the system of textual knowledge. The associative relations in the text allow highlighting in the organization of text the associative principle. It promotes the knowledge (information) objectification stored in human memory. 
Based on the associative relations, the author's intention in the process of text formation is converted into a system of images, and we can code it by linguistic means. The availability of the associative relations in the text is caused by the gnosiological and semiological aspect of the language category and by the possibility of storing, organizing, and transferring to the values of the language units of the socio-historical experience acquired in the process of cognition of the objective reality. Association in the text results from the established by the addresser associative relations (both background and text). These relations determine the nomination of the fragment of extralinguistic reality.

Associative relations, fixing the received knowledge are involved in both the emergence and the functioning of a verbal sign. Mandatory value also provides the mandatory associations that surround the word in the consciousness of the native speaker. The association defines the ability to use words in the text and provide its understanding correlating it with other text units and systems of languages.

Thus, for example, in a fragment from the novel by Maugham (2007) "The Moon and Sixpence," we selected the converged author's digression that author combined with the text of the story using the associative cohesion:

I asked myself whether was not in his soul some deeply rooted instinct of creation, which the circumstances of his life had obscured, but which grew relentlessly, as cancer may grow in the living issues, till at last it took possession of his whole being and forced him irresistibly to action. The cuckoo lays its eggs in the strange bird's nest, and when the young one is hatched, it shoulders its foster - brothers out and breaks, at last, the nest that has sheltered it. (Maugham, 2007).

With this author's digression, the author using the clear image of a mother cuckoo and cuckoochild, explains to the addressee how the instinct of creativity in the main character Strickland destroyed his family and life principles. When the hero faces a choice between art and family, he chooses art. Both the retrospection and the appraisal modality here are apparent. Retrospection acts in the reader's understanding of the information displayed in the author's digression; he should know the previous information. Thus, here a relation of an associative plan emerges.

The analyzed texts of the author's digression illustrate the specificity of functioning of the associative index in the text. While it is decoding in the reader's mind, a certain amount of information is updated, which is then "narrowed down" with a context. The availability of the associative indices in the text decodes the last discrete, which provides appealing the reader's background knowledge. Understanding the semantic content stored in the associative indicator (background or text) is based on an appropriate system of knowledge stored in the reader's memory.

\section{Conclusions}

The author's digressions can be both integrated and non-integrated. We found the following types of cohesion between the author's digression and the text: grammatical: conjunctions and connecting words, deictic means, participial phrases, semantic and associative types of cohesion. The author reaches the semantic unity of text and the author's digression with the synonymous 
repetitions. The author's digressions and the text of the main narrative are combined to express common emotions, feelings, and moods. Often the author's digression is the original author's emotional reaction to the current events. The author's digressions are often hyponymical with the text of the main narrative. Studies of the cognitive aspect of the author's digression in the different literary texts of English and American prose are promising.

\section{About the Author:}

Dr. Iryna Arkhipova is an Associate Professor at the Department of Germanic Philology, Faculty of Romance and Germanic Languages, Horlivka Institute for Foreign Languages HSEE "Donbas State Pedagogical University" (Bakhmut, Ukraine). Ph.D. in Philology (Germanic Languages). Her major research interests include Linguistics, Pragmatics, Stylistics, and Discourse Analysis. https://orcid.org/0000-0001-5536-2779

\section{References}

Bal, Mieke, (2009). Narratology: Introduction to the Theory of Narrative. Toronto: University of Toronto Press.

Benedetti, G. (2015), The Semantics of Grammatical Elements: A New Solution. International Journal of Language and Linguistics. 3 (6), 493-509. http://article.sciencepublishinggroup.com/

Bošković, Ž. (2016), Getting Really Edgy: On the Edge of the Edge. Linguistic Inquiry. 47(1), 133. http://dx.doi.org/10.1162/LING_a_00203

Britta, Mondorf, Javier Pérez-Guerra. (2016), Special issue on support strategies in language variation and change. Journal: English Language \& Linguistics. 20 (3) 383-393. DOI: https://doi.org/10.1017/S1360674316000289.

Crofft, W. (2004). Cognitive Linguistics Text. Cambridge, United Kingdom, Cambridge University Press.

Dijk, T.A. (1980). Macrostructures: an Interdisciplinary Study of Global Structures in Discourse, Interaction, and Cognition Text. Hillsdale, N.Y., Erlbaum Publ.

Galperin, I.R. (2014). Text as an Object of Linguistics Studies. Moscow, Russia; Editorial URSS.

Givon, T. (1993), Coherence in Text, Coherence in Mind. Pragmatics and cognition, (1), University of Oregon, Eugene.

Gordon, J.A. (2004). The movement of English Prose. London: Longman.

Green, G. (1990), Pragmatics and Natural Language Understanding. Journal of Linguistics, 26. (1), 277- 280.

Green, G. (2004). The Quiet American. Moscow, Russia: Manager.

Gumperz, J.J. (1982). Discourse Strategies. Cambridge: Cambridge University Press.

Halliday, M.A.K., Hasan R. (1976). Cohesion in English. London: Longman.

Kipling, R. (2021). The Light That Failed. https://www.gutenberg.org/files/2876/2876-h/2876h.htm

Klimkova, L.A. (1991), Associative Meanings of the Words in Literary Text. Philological Studies. (1), 45-54.

Kosmeda, T. (2017), Problems of Linguistics of Text Interpretation of Intimaxation Category. Linguistic Studies. (33), 103-108.

Kramar, N.U. (2017), Towards the Integrative Approach to Identity Construction in Academic Discourse. Linguistic Studies. (33), 113 - 120. 
Krongauz, M A. (2001). Semantics. Moscow, Russia: In-t Otkryitoe obschestvo.

Lyons, J. (1963). Structural Semantics: An Analysis of Part of the Vocabulary of Plato. Oxford: OF Publ.

Maugham, W. S. (2007). The Moon and Sixpence. https://www.gutenberg.org/files/222/222h/222-h.htm

Maugham, W.S. (2004). The Razor's edge. Moscow, Russia: Manager.

Priestley, J B. (2020). Angel Pavement. Moscow, Russia: Progress Publishing.

Redeker, G. (2000). Coherence and structure in text and discourse. Abduction, Belief, and Context in Dialogue. Studies in Computational Pragmatics. Amsterdam: Benjamins.

Scott, A. Crossley, Kristopher K. (2016), The tool for the automatic analysis of text cohesion (TAACO): Automatic assessment of local, global, and text cohesion. Behavior Research Methods. 48 (4), 1227-1237. https://link.springer.com/article/10.3758/s13428-015-0651-7

Selivanova, E.A. (2004). The Basis of Linguistic Theory of the Text and Communication. Kyiv, Ukraine.

Troshina, I.N. (1982), About Syntactic and Semantic Coherence in Literary Text. Aspects of General Linguistic Text Theory. (2), 50 - 74.

Turowetz, Jason (2017). On the Use of "I Just Thought" Formulations for Modifying One's Stance toward a Problematic Action. Research on Language and Social Interaction. (50), 115. https://doi.org/10.1080/08351813.2017.1375800 